phẫu thuật cấy ốc tai điện tử. Tạp chí Tai Mũi Họng Việt Nam.2020; 49-59.

4. Toner FM, Sanli $\mathbf{H}$, et al. Intraoperative Cochlear Implant Reinsertion Effects Evaluated by Electrode Impedance. Otology \& Neurotology. 2020;41(6): e695-e699.

5. Wilk $M$, Hessler $R$, Mugridge $K$, et al. Impedance Changes and Fibrous Tissue Growth after Cochlear Implantation Are Correlated and Can Be Reduced Using a Dexamethasone Eluting Electrode. Yamamoto M, ed. PLoS ONE. 2016; 11(2): e0147552.

6. Fu- Wei,Tao- Hsin Tung, et al. Evolution of impedance values in cochlear implant patients after early switch-on. PLoS One. 2021; 16(2): e0246545.

7. Brill S, Müller J, Hagen R, et al. Site of cochlear stimulation and its effect on electrically evoked compound action potentials using the MED-EL standard electrode array. BioMed Eng OnLine. 2009; 8(1):40.

8. Ramos BF, Tsuji RK, Bento RF, et al. Hearing preservation using topical dexamethasone alone and associated with hyaluronic acid in cochlear implantation. Acta Oto-Laryngologica. 2015; 135(5): 473-477.

\title{
MộT Số ĐẶC ĐIỂM DİCH TỄ HỌC, CÁC YẾU Tố THờI TIẾT, VÉC TO' TRUYỀN BÊNH SỐT XUẤT HUYẾT DENGUE TẠI HUYỆN THANH TRİ, THẦNH PHỐ HÀ NộI, GIAI ĐOẠN 2016-2020
}

\section{TÓM TẮT}

Mục tiêu: Nghiên cứu nhằm 2 mục tiêu, bao gồm mô tả một số đặc điểm dịch tễ của bênh Sốt xuất huyết Dengue và phân tích một số yếu tố thời tiết, véc tơ truyền bệnh của bệnh Sốt xuất huyết Dengue trên địa bàn huyện Thanh Trì, giai đoạn 2016-2020. Đối tượng và phương pháp nghiên cứu: Nghiên cứu sử dụng phương pháp mô tả cắt ngang có phân tích kết hợp hôi cứu toàn bô 4300 hồ sơ các ca bệnh SXHD được báo cáo và ghi nhận tại Trung tâm y tế huyện Thanh Trì, thành phố Hà Nối từ ngày 01/01/2016 đến ngày 31/12/2020. Kết quả: Hàng năm, số ca mắc SXHD tâp trung nhiều vào lứa tuổi từ 16 đến 45 , với nhóm tuổi từ 16-30 là 1389 ca và nhóm tuổi từ 31-45 là 1243 ca bệnh. Trong số 4438 ca bênh SXHD có sư tương đồng về giới tính, nam giới (2260, chiếm $50,9 \%)$; nữ giới (2178 ca, chiếm 49,1\%). Kết quả sử dụng kiểm định spearman cho thấy, mối liên quan giữa lượng mưa và số ca mắc SXHD của huyện Thanh Trì giai đoạn 2016 - 2020 là liên quan đồng biến ở mức trung bình với $r=0,1$, mối liên quan giữa nhiêtt độ và số ca mắc SXHD là liên quan đồng biến ở mức trung bình với $r=0,2$. Mối liên quan giữa lượng mưa và chỉ số BI aegypti SXHD là mối liên quan chặt chẽ với $r=0,6$. Mối liên quan giữa nhiệt độ và chỉ số $B I$ aegypti là mối liên quan chặt chẽ với $r=0,6$. Kết luận: Tại huyện Thanh Trì, giai đoạn 2016-2020, số ca bênh SXHD có xu hướng không đồng đều theo năm. Các trường hợp mắc SXHD cao nhất từ tháng 7 đến tháng 12 , thấp nhất từ tháng 1 đến tháng 4 , đỉnh

*Trung tâm Y tế dự phòng Thanh Tri **Đai hoc Y Hà Nội

Chịu trách nhiệm chính: Phạm Đăng Quân

Email: quanphamdang83@gmail.com

Ngày nhận bài: 2.7.2021

Ngày phản biên khoa hoc: 31.8.2021

Ngày duyệt bài: 6.9.2021

\section{Phạm Đăng Quân*, Chu Văn Thăng**, Trần Thu Phương*, Nguyễn Thị Ngọc Bích*}

dịch là vào tháng 8 . Mối liên quan giữa chỉ số BI aegypti và $\mathrm{BI}$ albopictus với số ca mắc SXHD là liên quan đồng biến ở mức trung bình. Mối liên quan giữa lượng mưa và nhiệt độ với chỉ số BI aegypti SXHD là các mối liên quan chặt chẽ

Tư khóa: Sốt xuất huyết Dengue; yếu tố thời tiết; vecto truyền bệnh; nhiệt độ; lượng mưa; độ ẩm.

\section{SUMMARY \\ EPIDEMIOLOGICAL CHARACTERISTICS, WEATHER FACTORS AND VECTORS OF DENGUE HEMORRHAGIC FEVER IN THANH} TRI DISTRICT, HANOI, 2016-2020

Purpose: The study aimed to describe epidemiological characteristics of Dengue Hemorrhagic Fever and to analyse weather factors and vectors of Dengue Hemorrhagic Fever in Thanh Tri District, 2016-2020. Materials and Methods: The study conducted cross-sectional descriptive method with retrospective analysis in total of 4,300 records of dengue cases reported and recorded at the Thanh Tri District Health Center, Hanoi from $1^{\text {st }}$ Jan, 2016 to $31^{\text {st }}$ Dec, 2020. Results: Every year, the number of dengue cases is highest in the age group from 16 to 45 , with 1389 cases in the 16-30 age group and 1243 cases in the 31-45 age group. Among 4438 dengue cases, male (2260, accounting for $50.9 \%$ ); women (2178 cases, accounting for $49.1 \%$ ). The results of using spearman test show that the association between precipitation and the number of dengue cases in Thanh Tri district in the period $2016-2020$ is positively related at an average level with $r=0.1$, the association between temperature and the number of dengue cases were positively related on average with $r=0.2$. The association between precipitation and BI aegypti dengue is significant with $r=0.6$. The association between temperature and aegypti BI is significant with $r=0.6$. Conclusion: In Thanh Tri district, 2016-2020, the number of dengue cases tends 
to be uneven by year. The highest dengue cases are from July to December, the lowest from January to April, the peak is in August. The association between BI aegypti and BI albopictus with the number of dengue cases is co-related variable on average. The association between rainfall and temperature with $\mathrm{BI}$ aegypti dengue is closely related.

Keywords: Dengue hemorrhagic fever; Dengue Fever; weather factors; vectors; temperature; precipitation; humidity.

\section{I. ĐẶT VẤN ĐỀ}

Hiện nay, bệnh Sốt xuất huyết Dengue (SXHD) đang có chiều hướng gia tăng phức tạp với tỷ lệ ước tính khoảng 100 triệu trường hợp có triệu chứng mỗi năm và xấp xỉ 300 triệu trường hợp nhiễm trùng không triệu chứng [1]. Bệnh thường gây thành dịch và lầy truyền do hai lioài muỗi vằn là Aedes aegypti và Aedes albopictus mang vi rút Dengue gây nên, trong đó quan trọng nhất là Aedes aegypti. Ở nước ta, dịch sốt xuất huyết Dengue xảy ra theo mùa và có sư khác biệt giữa miền Bắc và miền Nam. Ở miền Bắc thuộc vùng khí hậu cận nhiệt đới với bốn mùa rõ rệt, bệnh thường xảy ra từ tháng 4 đến tháng 11 đó là thời điểm khí hậu nóng, ẩm, mưa nhiêu rất thích hợp cho muỗi Aedes sinh trưởng và phát triển. Số bệnh nhân tăng lên rất nhanh từ tháng 7 đến tháng 11 , mà đỉnh cao là tháng 8,9 và 10 [2]. Sự gia tăng của tình trạng SXHD tại Hà Nội có liên quan đến đến thời tiết khí hậu. Sự lan truyên bệnh thể hiện ở các chu kỳ hàng năm, có sự gia tăng theo mùa về nhiệt độ trung bình và lượng mưa. Những thay đổi do khí hậu thúc đẩy sự sống sót của véc tơ. Những biến đỗi thời tiết còn có thể ảnh hưởng tới thời gian muỗi lây nhiễm sang người $[3,4,5]$. Huyện Thanh Trì có tốc độ đô thị hóa nhanh, phát triển nhiều khu chung cư cao tâng, dân cư đông đúc, nhiêuu trường đại học và cao đẳng trên địa bàn huyện nên di biến động dân cư lớn, nhiều lao động ngoại tỉnh, học sinh, sinh viên ngoại tỉnh thuê trọ nhiều cùng với những khu buôn bán phế liệu, phế thải và khu sinh hoạt không đảm bảo vệ sinh, nhà ở chật chội, tình trạng thiếu nước sạch, vệ sinh môi trường còn nhiều thách thức là những yếu tố thuận Iợi cho bệnh truyên nhiễm phát sinh, phát triển đặc biệt là bệnh sốt xuất huyết Dengue. Trên địa bàn huyện Thanh Trì, giai đoạn từ năm 2016 đến năm 2020 dịch sốt xuất huyết Dengue bùng phát trên toàn huyện, số ca mắc sốt xuất huyết Dengue thường ở mức cao, là một trong những điểm nóng về sốt xuất huyết Dengue và thường đứng trong tốp 8/30 quận huyện của Thành phố Hà Nội. Năm 2017 tỷ lệ mắc trung bình toàn thành phố là 492/100.000 dân, huyện Thanh Trì tỷ lệ mắc là 1234,4/ 1090.000 dân, cao gấp 2,5 lần.

\section{II. Đốl TƯợNG VÀ PHƯƠNG PHÁP NGHIÊN CứU}

1.1 Thiết kế nghiên cứu. Sử dụng phương pháp nghiên cứu mô tả cắt ngang có phân tích kết hợp hồi cứu toàn bộ 4300 hồ sơ các ca bệnh SXHD được báo cáo và ghi nhận tại Trung tâm y tế huyện Thanh Trì, thành phố Hà Nội giai đoạn 2016-2020. Nghiên cứu sử dụng phuowgn pháp chọn mẫu thuận tiện dựa trên số liệu sẵn có tại Trung tâm $Y$ tế huyện Thanh Trì, Tp. Hà Nội.

1.2 Kỹ thuật và công cụ nghiên cứu. Trích xuất toàn bộ hồ sơ, báo cáo các trường hợp mắc, tử vong do SXHD tại huyện Thanh Trì thành phố Hà Nội từ ngày 01/01/2016 đến 31/12/2020 được Trung tâm y tế huyện Thanh Trì, thành phố Hà Nội tổng hợp và báo cáo theo đúng quy định.

Quá trình thu thập, tổng hợp dữ liệu trong nghiên cứu này được chúng tôi thực hiện qua các bước sau:

Bước 1: Xin sự chấp thuận đồng ý cho sư dụng số liệu từ đơn vị chủ quản.

Bước 2: Thu thập dữ liệu báo cáo tháng các trường hợp mắc, tử vong SXHD, dữ liệu phiếu điều tra ca bệnh SXHD và kết quả xét nghiệm các ca bệnh SXHD từ năm 2016 - 2020 được lưu giữ tại Khoa Kiểm soát Bệnh tật và HIV/AIDS, Trung tâm $Y$ tế huyện Thanh Trì, thành phố Hà Nội.

Bước 3: Tổng hợp, thống nhất danh sách ca bệnh.

Bước 4. Tiến hành nhập liệu và xử lý số liệu.

\section{KẾT QUẢ NGHIÊN CỨU}

\section{Một số điểm dịch tễ của bệnh Sốt xuất} huyêt Dengue

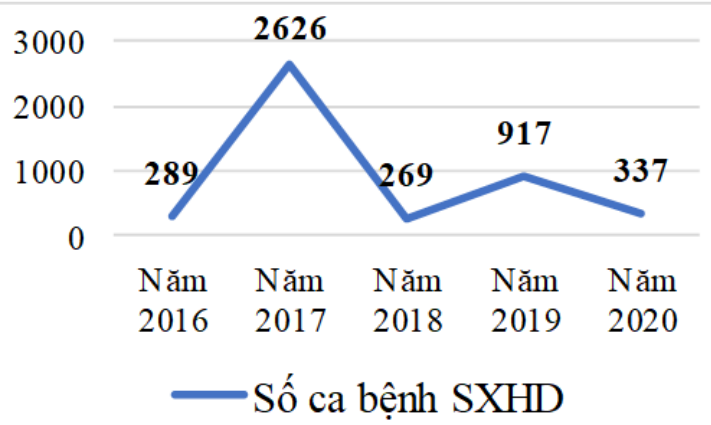

\section{Biểu đồ 1: Phân bố ca bệnh SXHD tại huyện Thanh Tri giai đoan 2016- 2020}

Từ năm 2016 đến nắm 2020, số ca bệnh SXHD tại huyện Thanh Trì có xu hướng khổng đồng đểu, tỷ lệ mắc cao nhất vào năm 2017 với 2626 ca bệnh và thấp nhất vào năm 2018 là 269 ca bệnh. 


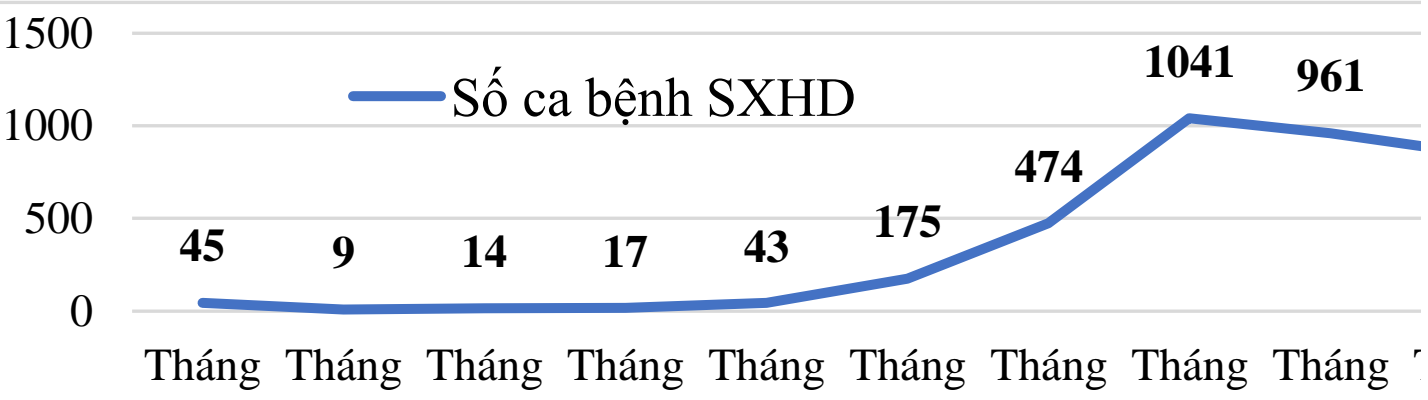

Biểu đồ 2: Phân bố bệnh SXHD tại huyện Thanh Tri giai đoạn 2016- 2020 theo tháng

Giai đoan 2016-2020 các trường hợp mắc SXHD cao nhất từ tháng 8 đến tháng 10 , thấp nhất từ tháng 1 đến tháng 5 . Đỉnh dịch SXHD tại Thanh Trì là tháng 8.

Bảng 1: Phân bố bố bênh SXHD tại huyện Thanh Tri giai đoạn 2016- 2020 theo tuối

\begin{tabular}{|c|c|c|c|}
\hline \multicolumn{2}{|c|}{ Đặc trưng cá nhân } & $\begin{array}{c}\text { Số lượng } \\
\text { (n) }\end{array}$ & $\begin{array}{l}\text { Tỷ lệ } \\
\text { \% }\end{array}$ \\
\hline \multirow{6}{*}{$\begin{array}{l}\text { Nhóm } \\
\text { tuổi }\end{array}$} & Dưới 5 & 103 & 2,3 \\
\hline & Từ 5 - 15 & 628 & 14,2 \\
\hline & Từ 16 - 30 & 1389 & 31,3 \\
\hline & Từ 31 - 45 & 1243 & 28,0 \\
\hline & Từ $46-60$ & 734 & 16,5 \\
\hline & Trên 60 & 341 & 7,7 \\
\hline
\end{tabular}

Hàng năm, số ca mắc SXHD tập trung nhiều vào lứa tuổi từ 16 đến 45

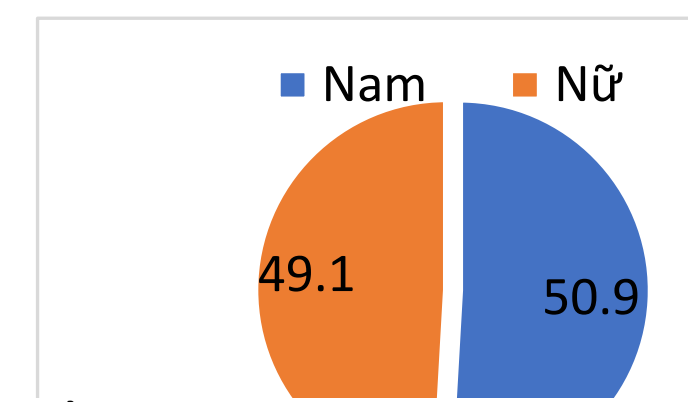

Biểu đồ 3: Phân bố bệnh SXHD tại huyện Thanh Tri giai đoan 2016- 2020 theo giới

Trong số 4438 ca bệnh SXHD có sự tương đồng về giới tính, nam giới (2260, chiếm 50,9\%); nữ giới (2178 ca, chiếm 49,1\%).

Một số yếu tố thời tiết, véc tơ truyên bệnh của bệnh Sốt xuất huyết Dengue

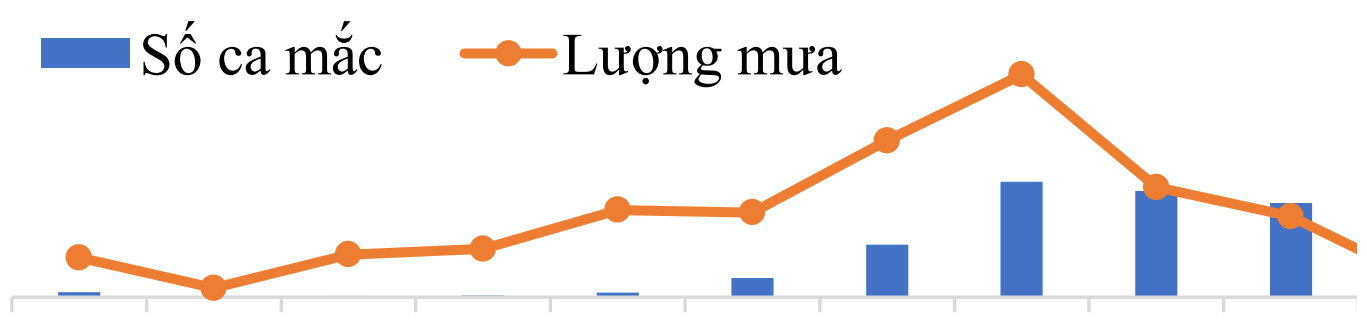

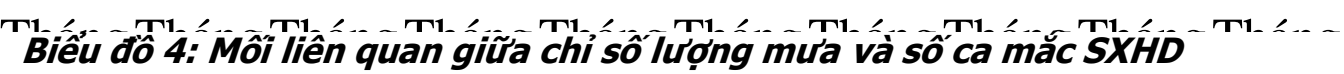
của huyên Thanh Tri giai đoạn 2016-2020

Mối liên quan giữa lượng mưa và số ca mắc SXHD của huyện Thanh Trì giai đoạn 2016 - 2020 là liên quan đồng biến ở mức trung bình với $r=0,1$.

Số ca mắc —-Nhiệt độ

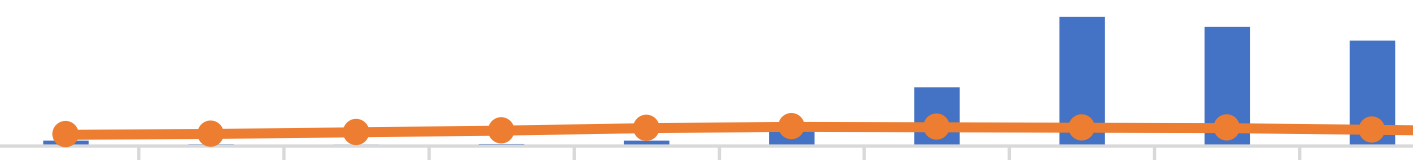

Tháng Tháng Tháng Tháng Tháng Tháng Tháng Tháng Tháng Thán Biểu đồ 5 Môi liên quan giữa chi số nhiệt độ và số ca mắc SXHD của huyện Thanh Tri giai đoạn 2016-2020 
Mối liên quan giữa nhiệt độ và số ca mắc SXHD của huyện Thanh Trì giai đoạn 2016 - 2020 là liên quan đồng biến ở mức trung bình với $r=0,2$.

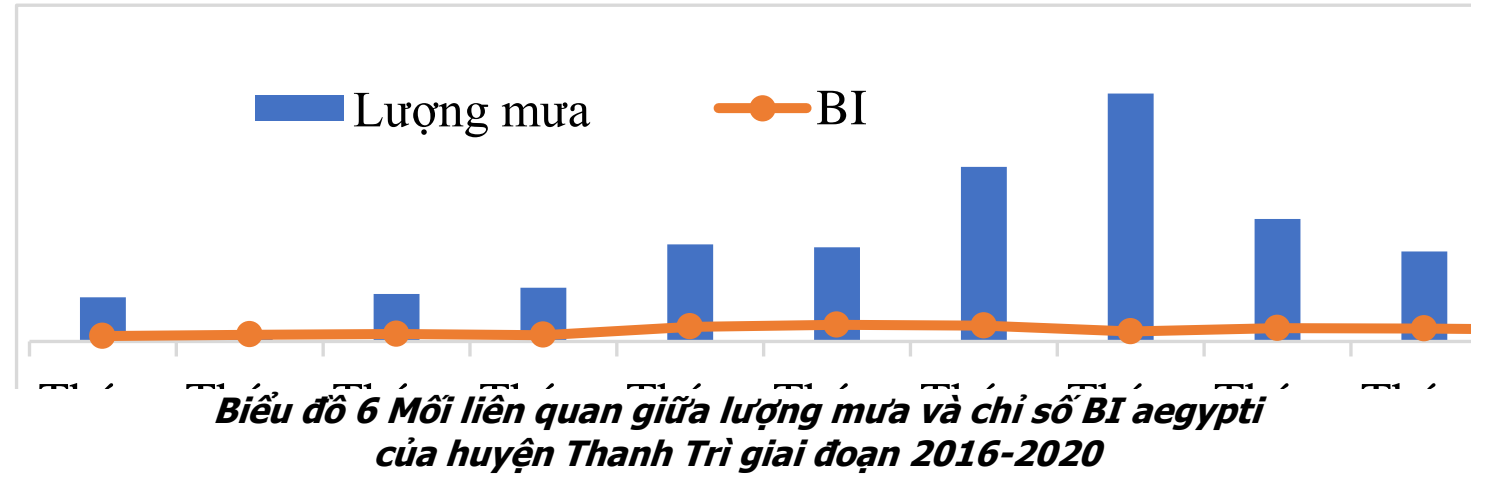

Mối liên quan giữa lượng mưa và chỉ số BI aegypti SXHD của huyện Thanh Trì giai đoạn 2016 2020 là mối liên quan chặt chẽ với $r=0,6$.

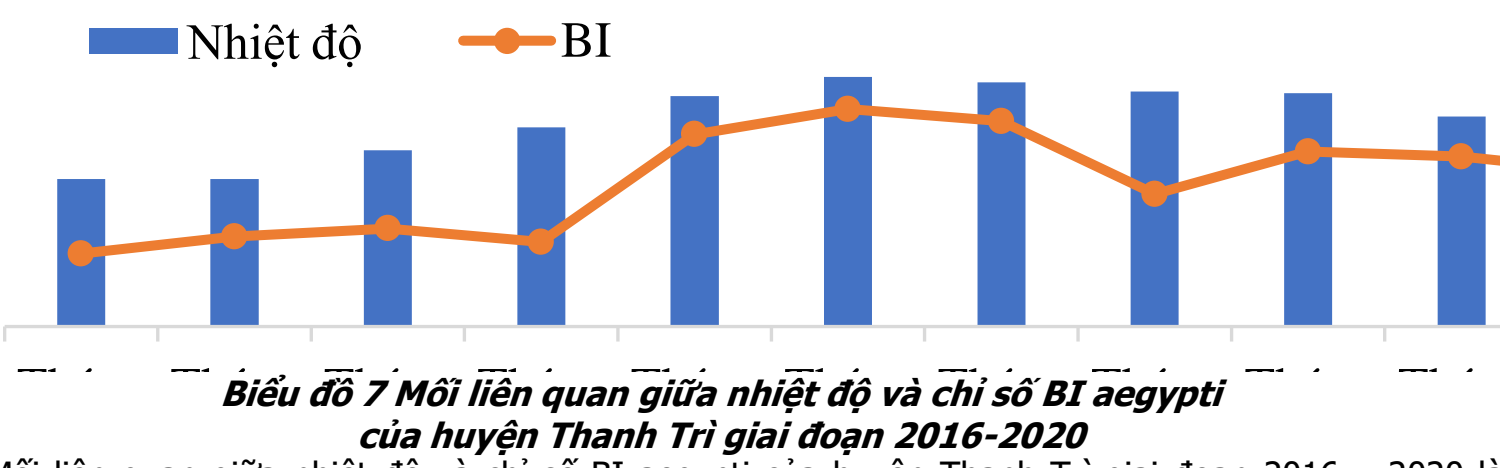

Mối liên quan giữa nhiệt độ và chỉ số BI aegypti của huyện Thanh Trì giai đoạn 2016 - 2020 là mối liên quan chặt chẽ với $r=0,6$.

\section{BÀN LUÂN \\ Một số điểm dịch tễ của bệnh Sốt xuất huyêt Dengue}

Tình hình mắc do SXHD theo thời gian. Từ năm 2016 đến năm 2020, số ca mắc SXHD tai Thanh Trì có diễn biến phức tap không có tính chu kì, một năm tăng rồi một năm giảm. Số ca mắc tăng đột biến từ 289 ca năm 2016 lên 2626 ca năm 2020. Kết quả nghiên cứu cũng phù hợp với tỷ lệ bùng phát dịch bệnh tái phát trong 9 năm tại Hà Nội ở 4 quận giáp ranh đó là Đống Đa, Thanh Xuẩn, Hoàng Mai, Thanh Trì [6]. Tỷ lệ mắc $S X H D / 100.000$ dân cao nhất vào năm 2017 với 1187,6 trường hợp và thấp nhất vào năm 2018 với 112,5 trường hợp. So sánh với cả nước, tỷ lệ mắc sốt xuất huyết tại Thanh Trì vẫn còn ở mức rất cao [7]. Kết quả nghiên cứu chỉ ra rằng, tỷ lệ tăng cao các trường hợp sốt xuất huyết tại Thanh Trì bắt đầu từ tháng 7 đến tháng 12 , đỉnh dịch là tháng 8 , thời điểm bắt đầu mùa mưa. Kết quả nghiên cứu phù hợp với các nghiên cứu trước đó về đặc điểm dich tễ học SXHD tại Hà Nội là số ca bệnh chủ yếu tập trung vào tháng 7 đến tháng 12 [3].

Tình hình mắc do SXHD theo tuổi. Bệnh SXHD tại Thanh Trì gặp ở tất cả các lứa tuổi, trong đó tỷ lệ mắc SXHD ở nhớm tuổi $>15$ tuối cao hơn nhóm tuổi $<15$ tuổi trong 5 năm nghiên cứu. Giải thích về nguyên nhân này, chúng tôi nhận thấy Thanh Trì là một huyện giáp ranh nội thành, có những khu công nghiệp, trường học, dân cư đông đúc, số lượng mắc sốt xuất huyết cao chủ yếu ở sinh viên và công nhân.

Tình hình mắc do SXHD theo giới. Trong nghiên cứu, nam giới có tỷ lệ mắc 50,9\% cao hơn so với nữ giới với tỷ lệ $49,1 \%$. Nghiên cứu này của chúng tôi phù hợp với nghiên cứu của các tác giả như Đào Thị Minh An (2014), Đỗ Thị Thanh Toàn (2010) hay Nguyển Nhật Cảm (2013) đều chỉ ra rằng không có sự khác biệt về giới giữa các ca bệnh sốt xuất huyết $[6,8,9]$.

Một số yếu tố thời tiết, véc tơ truyên bệnh của bệnh Sốt xuất huyết Dengue

Mối liên quan giữa yếu tố thời tiết và chỉ số BI. Có sự tương đồng giữa các yếu tố thời tiết với chỉ số BI. Nhiệt độ trung bình thấp nhẩt trong 
năm được ghi nhận vào tháng 1 và tháng 2 , và cao nhất ở tháng 6 và tháng 7. Kèm theo đó chỉ số $\mathrm{BI}$ aegypti thấp nhất cũng rơi vào tháng 1 và tháng 2, chỉ số BI albopictus thấp nhất rơi vào tháng 1 và tháng 3 . Chỉ số BI aegypti cao nhất rơi vào tháng 6 và tháng 7 , chỉ số $B I$ albopictus cao nhất rơi vào tháng 5 và tháng 7 .

Mối liên quan của ca bệnh với yếu tố lượng mưa là mối liên quan trung bình. Lượng mưa tại tháng 7 đạt mức độ cao nhất, kéo theo đó chỉ số $B I$ aegypti và $B I$ albopictus cũng tăng.

Theo nghiên cứu của Michael A. Johansson, nhiệt độ và lượng mưa có tác động đến sự lây truyền của bệnh sốt xuất huyết thông qua tác động của chúng đến quần thể véc tơ.

Mối liên quan giữa yếu tố thời tiết và số ca mắc sốt xuất huyết. Những số liệu về ca mắc và số liệu về các yếu tố thời tiết cho chúng tôi thấy có mối liên quan với nhau. Tháng có ca bệnh mắc cao nhất trong năm là tháng 8 , tháng có ca mắc bệnh thấp nhất là tháng 2 và tháng 3 .

Theo nghiên cứu của Micheal $A$. Johansson và các cộng sự, do ảnh hưởng của hiện tượng biến đổi thời tiết đặc biệt là hiện tượng El Nino sẽ làm giảm lượng mưa từ đó khiến cho người dân sử dụng các chum vại để chứa nước. Tữ đó làm gia tăng địa điểm sinh sản của muỗi và hậu quả là dẫn đển sự lây truyên của sốt xuất huyết. Bên cạnh đó, trong những năm gần đây, Thanh Trì với tốc độ phát triển vượt trội về kinh tế kéo theo hình thành các khu nhà trọ cho công nhân, người lao đông tự do với điều kiên sinh hoat kém. Đó chính là những ổ bệnh tự nhiên của muỗi.

\section{KẾT LUẬN}

Một số đặc điểm dịch tễ của bênh Sốt xuất huyết Dengue. Năm 2017, số mắc SXHD tại Thanh Trì có chiều hướng tăng rõ rệt so với năm 2016. Đến năm 2018 thì số ca mắc lại giảm còn 269 ca. Tuy nhiên đến năm 2019, số ca bệnh của địa phương lại tăng với $917 \mathrm{ca}$.

Các trường hợp mắc SXHD cao nhất từ tháng 7 đến tháng 12, thấp nhất từ tháng 1 đến tháng 4. Đỉnh dịch là vào tháng 8 .

Tỷ lệ mắc SXHD của nam và nữ tương đương nhau với $50,9 \%$ của nam và $49,1 \%$ của nữ

Tỷ suất mắc/100.000 dân tại Thanh Trì giai đoạn 2016-2020 cao nhất vào năm 2017 với 1187,6 trường hợp và thấp nhất là năm 2018 với 112,5 trường hợp.

Một số yếu tố thời tiết, véc tơ truyền bệnh của bệnh Sốt xuất huyết Dengue. Mối liển quan giữa chỉ số $\mathrm{BI}$ aegypti và $\mathrm{BI}$ albopictus với số ca mắc SXHD là liên quan đồng biến ở mức trung bình với $r$ lần lượt $=0,3$ và 0,4 .

Mối liên quan giữa lượng mưa và số ca mắc SXHD là liên quan đồng biến ở mức trung bình với $r=0,1$.

Mối liên quan giữa nhiệt độ và số ca mắc SXHD là liên quan đồng biến ở mức trung bình với $r=0,2$.

Mối liên quan giữa lượng mưa và chỉ số $\mathrm{BI}$ aegypti SXHD là mối liên quan chặt chẽ với $r=0,6$.

Mối liên quan giữa lượng mưa và chỉ số $\mathrm{BI}$ albopictus là mối liên quan trung bình với $r=0,2$.

Mối liên quan giữa nhiệt độ và chỉ số $B I$ aegypti là mối liên quan chặt chẽ với $r=0,6$.

Mối liên quan giữa nhiệt độ và chỉ số BI albopictus là mối liên quan trung bình với r=0,5.

\section{TÀI LIỆU THAM KHẢO}

1. Dengue and severe dengue. Accessed March 7 2021. https://www.who.int/westernpacific/healthtopics/dengue-and-severe-dengue,

2. NTL Trân Thanh Dương, Nguyễn Hoàng Long, Trần Thị Oanh, Phan Trong Lân. Phân tích đặc điểm bệnh sốt xuất huyết Dengue giai đoạn 20092012 tại Việt Nam. Tạp chí y học dự phòng. 2015;8(135):106-112.

3. Cuong $H Q$, Hien NT, Duong $T N$, et al. Quantifying the Emergence of Dengue in Hanoi, Vietnam: 1998-2009. PLOS Neglected Tropical Diseases. 2011;5(9):e1322. doi:10.1371/ journal.pntd.0001322

4. Johansson MA, Cummings DAT, Glass GE. Multiyear Climate Variability and Dengue-El Niño Southern Oscillation, Weather, and Dengue Incidence in Puerto Rico, Mexico, and Thailand: A Longitudinal Data Analysis. PLOS Medicine. 2009;6(11):e1000168. doi:10.1371/journal.pmed.1000168

5. Rohani CA, Entomology M, Rohani $A$, et al. The effect of extrinsic incubation temperature on development of dengue serotype. In: 2 and 4 Viruses in Aedes Aegypti (L.). Southeast Asian J. Trop. Med. Public Health 2009; 942-950.

6. Minh An DT, Rocklöv J. Epidemiology of dengue fever in Hanoi from 2002 to 2010 and its meteorological determinants. Global Health Action. 2014;7(s4):23074. doi:10.3402/gha.v7.23074

7. Thông tin tinh hình và hoạt động phòng chống dịch bênh sốt xuất huyết. Thông tin tinh hình và hoạt động phòng chống dịch bệnh sốt xuất huyêt. Accessed March 8, 2021. https://vncdc.gov.vn/thong-tin-tinh-hinh-va-hoatdong-phong-chong-dich-benh-sot-xuat-huyetnd14621. html

8. Nguyễn Minh Hải, Hoàng Đức Hạnh, Nguyễn Nhật Cảm, Đặng Thi KimHanh. Một số đặc điểm dịch tế học bệnh sốt xuất huyết Dengue ở Hà Nội giai đoạn 2006 - 2011. 2013;23(2):58-65.

9. Do IIT, Martens $P$, Luu NH, Wright $P$, Choisy M. Climatic-driven seasonality of emerging dengue fever in Hanoi, Vietnam. BMC Public Health. 2014;14(1):1078. doi:10.1186/1471-2458-14-107. 